\title{
TENSÕES E DISPUTAS NA SOCIOLOGIA PAULISTA (1940-1970)
}

\section{Luiz Carlos Jackson}

Este artigo interpreta as décadas de formaÇão da sociologia paulista (1940-1970) a partir das principais disputas entre instituições, grupos e atores, ocorridas nesse contexto unificado pela tentativa de explicar a recalcitrante modernização brasileira. Nessa direção, as sociologias específicas progressivamente constituídas eram antes perspectivas de análise do que especialidades propriamente ditas. A exposição toma como referência pares de alternativas, em torno dos quais havia divergência: ensaio e ciência, pensamento radical e conservador, teoria e pesquisa empírica, interpretações totalizadoras e dualistas, sociologia do desenvolvimento e da cultura. A partir dessas oposições, que não devem ser compreendidas rigidamente, as tensões constitutivas do período são demarcadas.

Artigo recebido em fevereiro/2006 Aprovado em abril/2007

\section{Do ensaio à ciência}

Em conjunto, pode-se dizer que as modificações introduzidas enriquecem a obra, tanto do ponto de vista literário, quanto do ponto de vista da documentação coligida e de sua elaboração.

Mas isso significa também que as principais virtudes do ensaio foram mantidas juntamente com alguns de seus defeitos. O ensaísta revelou-se de uma maestria e de uma penetração inigualáveis na sugestão de problemas. Poucos especialistas poderão atravessar as páginas do ensaio sem encontrar alguma indicação de pistas para pesquisa ou investigação, sejam historiadores, psicólogos sociais, antropólogos, sociólogos ou economistas. Na reconstrução de um processo histórico-social tão complexo, como é o desenvolvimento do Brasil, contudo, nem sempre consegue superar, com a mesma felicidade e equilíbrio, as limitações impostas pelos insuficientes conhecimentos que ainda hoje dispomos de nosso passado. Toda tentativa de síntese é empolgante e fecunda; mas os riscos são tanto maiores quanto mais inconsistente se revela a base empírica e 
analítica sobre a qual se constrói [....]. Observa-se, igualmente, uma ênfase excessiva nos aspectos da cultura. Isso traduz, provavelmente, a influência da abundante literatura etnológica conhecida pelo autor. Mas, tem vários inconvenientes, já que leva a subestimar os efeitos e determinações da organização social. Muitos dos problemas encarados apenas da perspectiva da cultura, como os que dizem respeito à situação de contato no Brasil colonial (século XVI, especialmente) ou os resultados da secularização da cultura e da urbanização, poderiam ser discutidos de um ponto de vista sociológico, único capaz de pôr em evidência a atuação dos processos sociais subjacentes aos ajustamentos e às mudanças culturais. A própria natureza e amplitude da obra compensam e neutralizam, no entanto, as pequenas insuficiências desta ordem, e a tornam tão indispensável ao sociólogo quanto ao historiador cultural (Fernandes, 1949, pp. 223-224).

A passagem, que finaliza a resenha de Florestan Fernandes sobre a segunda edição de Raízes do Brasil (1948) é muito significativa para avaliarmos a ruptura realizada no país pelos cientistas sociais paulistas - especialmente na Faculdade de Filosofia Ciências e Letras da Universidade de São Paulo (FFCL-USP) - em relação aos intelectuais não acadêmicos dos anos de 1930 e 1940, que se expressavam, sobretudo, através do ensaio histórico sociológico ${ }^{1}$ - gênero indefinido entre literatura, sociologia, história -, interpretando de forma abrangente o processo de formação da sociedade e da nação, em meio à radicalização política que seguiu a Revolução de $1930 .^{2}$

A investida de Florestan incide já no elogio algo irônico à qualidade literária de Raizes, mas é na desproporção entre a generalidade da interpretação e a precariedade de dados empíricos e recursos analíticos que reside o fulcro da crítica do sociólogo. Este, diga-se, ainda não totalmente consagrado em 1949, mas já bastante respeitado pelos trabalhos sobre o folclore paulista e, sobretudo, por Organização social dos Tupinambá, mestrado orientado por Herbert Baldus na Escola livre de Sociologia e Política (ELSP). O antropólogo alemão, aliás, havia sido recentemente convidado para chefiar a Seção de Etnologia do Museu Paulista e a editar a sua revista (em 1947) pelo então diretor do museu, Sérgio Buarque de Holanda. Impressiona, assim, a ousadia do jovem sociólogo ao atacar, embora reconhecendo a indiscutível importância do livro, a forma e os fundamentos da argumentação de Raízes do Brasil, que, ao mesmo tempo, seria inspiração e contraponto para o projeto acadêmico concretizado em A revolução burguesa no Brasil. ${ }^{3}$ O exemplo indica, portanto, a relação complexa que vincula as gerações de intelectuais e obras separadas pela institucionalização das ciências sociais iniciada com a criação da ELSP (1933) e da FFCL-USP (1934). Nesse sentido, a trajetória e a obra de Florestan não podem ser interpretadas rigidamente em oposição ao ensaísmo, do qual se aproxima em vários escritos, mesmo defendendo a busca de cientificidade como etapa indispensável ao desenvolvimento da sociologia no Brasil.

Em trabalho anterior (Jackson, 2002), procurei demonstrar a afinidade de Os parceiros do Rio Bonito tese de doutorado de Antonio Candido em sociologia (1954), publicada por José Olympio (1964) com as interpretações do Brasil destacadas pelo autor no prefácio à edição de 1967 do ensaio de Sérgio Buarque, ao qual se juntariam Formação do Brasil contemporâneo, de Caio Prado Jr. e Casa-grande \& senzala, de Gilberto Freyre. Sob a aparência de um "estudo de comunidade" ou duma "monografia antropológica", seria Os parceiros também uma interpretação global da formação social brasileira que privilegiaria nesse processo a participação das populações rústicas constituídas à margem dos latifúndios escravocratas, desde o século XVI.

Não tanto nesse caso, mas principalmente nas teses e livros produzidos pelo grupo de sociólogos liderado por Florestan Fernandes a partir de 1954, que formariam a "escola paulista de sociologia", a ruptura efetivamente realizada pelos estudos sobre a sociedade brasileira em São Paulo seria em geral superestimada, ${ }^{4}$ não por acaso, pois ela constituía antes um programa, constantemente reiterado, do que uma clivagem propriamente dita. Em outros termos, a continuidade verificada na recorrência de temas e linhas de interpretação de uma geração para outra representa o "outro lado da moeda", mais conhecida pela renovação de métodos, teorias e fundamentos empíricos. Em depoimento de Maria Sylvia de Carvalho e Franco, do início dos anos de 1970, a orientação desse programa é claramente definida: 
[...] o projeto [que predominava na USP nos anos de 1950 e 1960] de estabelecer as ciências sociais como disciplinas científicas autônomas, desdenhando-se tudo o que as aproximasse de "impressionismo". Havia o esforço decidido de transformá-las em saber positivo, desprezando-se seus aspectos humanísticos. Esta orientação definiu-se como crítica à "cultura de bacharel", encarada com desconfiança, vista como retórica superficial, estranha à reflexão gerada nas condições estruturais de nossa realidade. ${ }^{5}$

A oposição entre ensaio e ciência deve ser pensada, sugiro, como relação complexa, em torno da qual diferenciavam-se personagens ${ }^{6} \mathrm{e}$ grupos, mais ou menos envolvidos no projeto de opor a sociologia como ciência ao ensaio. Isso porque ninguém (na universidade) poderia fugir a essa orientação geral, decorrente do processo abrangente de legitimação das ciências sociais no período.

Em tal contexto, em que era essencial a construção duma identidade profissional específica, incorporam-se teorias e técnicas de pesquisa aqui aportadas pelos professores estrangeiros sobretudo os franceses na USP e os norte-americanos na ELSP além de novas formas de organização e avaliação do trabalho intelectual, ${ }^{7}$ tornando-se quase inevitável o fortalecimento de nova forma expressiva, ${ }^{8}$ em oposição à precedente, legitimada progressivamente.

Em meio a essa condição geral, como vimos, personagens e grupos se diferenciavam. Sabe-se, por exemplo, que Roger Bastide, que assume a segunda cadeira de sociologia ${ }^{9}$ em 1938 (no começo da década de 1940 passaria para a Sociologia I), substituindo Lévi-Strauss, interessou-se imediatamente pela leitura de autores brasileiros, indignando-se com a ignorância de muitos alunos a esse respeito e insistindo para que os estudassem. A obra de Bastide, e seu interesse pela realidade brasileira, não pode ser bem compreendida, como demonstrou Fernanda Peixoto (2000), se não conhecermos seu diálogo com autores brasileiros, como o modernista Mário de Andrade e o ensaísta (ou sociólogo) Gilberto Freyre.

Entre os alunos de Bastide, estavam Florestan Fernandes e Antonio Candido. Os dois encarnam pontos de vista quase opostos, expressos em textos decisivos das décadas de 1940,
1950 e 1960. Estamos diante de trajetórias concorrentes ${ }^{10}$ fundadas em experiências sociais distantes. Colegas de graduação em 1941, primeiro ano do curso para Florestan, último para Antonio Candido, depois assistentes de Fernando de Azevedo na cadeira de Sociologia II, até 1954, os dois trilharam caminhos distintos: o primeiro, exclusivamente dedicado à sociologia; o segundo, dividido entre sociologia e literatura, pelo menos até o final dos anos de 1950. Não é de se estranhar, assim, a diferença de pontos de vista; Antonio Candido estando mais próximo duma perspectiva humanística, como verificamos em textos como "A Sociologia no Brasil" e "Literatura e cultura de 1900 a 1945", nos quais o autor destaca, como forma típica de expressão do nosso pensamento, o "sincretismo" entre literatura e sociologia.

A forma ensaio não seria, nesse sentido, obstáculo para a radicalização do pensamento brasileiro, processo considerado decisivo para a transformação da sociedade. Ao contrário, a maior liberdade de expressão favoreceria a produção científica e a comunicação com o público, estimulando a intuição e a criatividade do pesquisador. Em "A sociologia no Brasil", Antonio Candido defende o "sincretismo", em contrapartida à valorização exclusiva da abordagem científica: "sincretismo que pode parecer indevido e talvez o seja em certa medida, mas corresponde a características da nossa evolução mental e necessidades ainda sentidas de compreensão da nossa realidade" (Candido, 1957, p. 2118). Certa indiferenciação intelectual permitiria ao "espírito e aos métodos sociológicos estenderem-se por vários setores que lhe estariam vedados em países de especialização acadêmica mais estrita, enriquecendo o conhecimento da realidade e facultando maior plenitude à personalidade dos estudiosos" (Idem, ibidem).

Se Antonio Candido aproxima-se de uma cultura humanística, Florestan, ao contrário, defende a sociologia como ciência, mesmo reconhecendo a importância heurística do ensaio para a explicação de nossa formação histórica e social. ${ }^{11}$ Para melhor avaliar essa oposição de perspectivas - em meio à orientação geral dada, como vimos, pela necessidade de construir uma identidade profissional coletiva que a todos 
incluísse -, vejamos ainda algumas evidências recolhidas das seções de resenhas dos periódi$\cos ,{ }^{12}$ fonte preciosa para o mapeamento das disputas, sobretudo em meio acadêmico rarefeito como era o das ciências sociais paulistas nos anos de 1940 e 1950. É indicativo desse fato que o próprio Antonio Candido escrevesse (em 1949) uma crítica sobre Organização social dos Tupinambá, na Revista do Museu Paulista (editada por Herbert Baldus), da qual reproduzimos duas passagens relevantes para a questão que nos ocupa:

Sendo o de menor interesse sociológico [o capítulo 1 do livro], talvez seja, não obstante, o que melhor ilustra as qualidades e as lacunas do autor: de um lado, a capacidade de percorrer incansavelmente os dados disponíveis, virando-os e revirando-os até a exaustão das suas possibilidades informativas; de outro, a insistência em aspectos porventura demasiados, que não contribuindo para uma conclusão segura, parecem utilizados mais como demonstração de força.

Numa resenha, não cabe censura nem louvor, mas simples exposição crítica. Se nos permitirem, porém, violar as normas, diríamos que o defeito capital do trabalho é a acentuada prolixidade de algumas partes e, aqui e ali, certo abuso de casuística. Nota-se ainda relativo descuido de expressão, que desejaríamos mais apurada num livro, que, como este, está destinado a carreira longa e brilhante (Candido, 1949, pp. 474-476).

Se há na resenha um tom elogioso, a crítica incide justamente na busca quase obsessiva de cientificidade, fator responsável paradoxalmente pelas qualidades e defeitos do trabalho, estes derivados também de "descuidos de expressão". Mas é preciso notar que a objeção apontada por Antonio Candido não é superficial, à medida que a forma expressiva para ele é parte essencial à argumentação científica. Curiosamente, Organização social dos Tupinambá é um dos textos menos truncados do ponto de vista da escrita, em comparação à maioria dos textos posteriores do autor. ${ }^{13}$

Igualmente significativa é a resenha de Florestan publicada na revista Anhembi sobre a tese de Gilda de Mello e Souza, orientada por Bastide, A moda no século XIX: ensaio de sociologia estética, ${ }^{14}$ que tinha sido publicada na Revista do Museu Paulista, vol. 5, em 1951. Depois do resumo cuidadoso do trabalho, deparamo-nos com a avaliação do sociólogo:
Tal como se apresenta, o trabalho da dra. Gilda de Mello e Souza revela duas coisas. Primeiro, o talento e a extraordinária sensibilidade da autora para a investigação de um fenômeno tão complexo, por causa das diversas facetas de que pode ser encarado e explicado. Segundo, um seguro conhecimento do campo de sua especialização, em um nível que até pouco tempo era raro no Brasil. Essas qualidades se refletem na composição do trabalho, tornando a sua leitura muito amena e instrutiva. Poder-se-ia lamentar, porém, a exploração abusiva da liberdade de expressão (a qual não se coaduna com a natureza de um ensaio sociológico) e a falta de fundamentação empirica de algumas das explanações mais sugestivas e importantes. Doutro lado, não concordamos com a afirmação da autora, segundo a qual "a moda, como toda manifestação do gosto, é traiçoeira e, quando analisada de perto, esconde suas feições mais características, induzindo o observador a erro" (p.10). A esse respeito, pensamos que uma das vantagens da abordagem sociológica do fenômeno consiste exatamente na possibilidade de compreendê-lo e interpretá-lo, através de técnicas de investigação adequadas, em suas manifestações no mundo em que vivemos, ou seja, como dimensões atuais do acontecer (Fernandes, 1952, p. 140, grifos meus).

O tom ambíguo de Florestan na crítica ao trabalho explica-se não apenas por sua qualidade intrínseca, mas também por afirmar, ao mesmo tempo, o padrão da instituição acadêmica, a FFCL-USP, na qual ocupavam posições equivalentes - a autora era assistente de Roger Bastide na Sociologia I. É o lamento do autor, entretanto, que mais nos interessa, sobretudo por inverter os parâmetros que guiaram a análise de Antonio Candido ao seu livro. Se o sociólogo falhara, na visão de seu colega, por falta de estilo, aqui o problema apontado era exatamente o contrário: excesso. ${ }^{15}$ Finalizando a crítica, a aposta nas possibilidades objetivas da explicação científica, um pouco matizadas na perspectiva sociológica da autora.

Mais um registro nos parece exemplar da tensão que envolvia a sociologia na Universidade de São Paulo, nos anos de 1950. Trata-se de outra resenha, agora de Octávio Ianni, sobre Sociologia, introdução ao estudo de seus princípios, de Gilberto Freyre, na qual o resenhista discute a concepção sociológica do autor de Casa-grande 
Esenzala, criticado por confundir linguagens distintas, arte e ciência:

Mas, examinemos outro aspecto dessa obra. Em diversas passagens verifica-se certa confusão entre o tipo de abstração que realiza o artista e aquela efetuada pelo cientista. Não é outro o significado das afirmações entusiásticas do autor a propósito de Proust. Veja-se o que ele afirma sobre esse autor às páginas 70 e 71 . Proust "consegue nos dar melhor que todos os discípulos de Durkheim juntos, o retrato psico-sociológico da aristocracia francesa no fim do século XIX e no começo do XX" [...]. "O que há em Proust é história sociológica, história psicológica”. Para Gilberto Freyre, o ficcionista francês é "historiador, sociólogo e psicólogo a um só tempo". E a sua superioridade sobre os discípulos de Durkheim não provém da "fantasia literária" nem da "graça de estilo" - tão fracas em Proust - mas da sua superioridade como "sociólogo psicológico". Deixando-se de lado outros comentários que poderiam suscitar essas afirmações, poderemos distinguir nelas duas ordens de confusões. Em primeiro lugar, aquela relativa ao significado de descrição e interpretação numa ciência como a sociologia, e em que medida esses procedimentos poderiam ser encontrados numa obra de ficção. Em segundo lugar, a abstração realizada pelo ficcionista distingue-se essencialmente, e não apenas em grau, daquela operada pelo cientista. Os elementos selecionados no processo de criação literária não são os mesmos, nem comparáveis às instâncias empíricas manipuladas pelo sociólogo. Portanto, aquelas considerações a propósito de Proust confundem modos de apreensão da realidade. A nosso ver, o que disse Florestan Fernandes a respeito da Filosofia, do mito e outras formas pré-científicas de consciência e explicação, pode ser aplicado ao romance. "Tais modalidades de representação da vida social nada tem em comum com a sociologia. Elas surpreendem, às vezes com espírito sistemático e profundidade crítica, facetas complexas da vida social. Também desempenharam ou desempenham, em seus contextos culturais, funções intelectuais similares às que cabem à sociologia da civilização industrial moderna: pois todas servem aos mesmos propósitos e às mesmas necessidades de explicação da posição do homem no cosmos". Na verdade, "elas envolvem tipos de raciocínio fundamentalmente distintos e opostos ao raciocínio científico" (Ianni, 1958, p. 356).

A passagem explicita a perspectiva de Florestan Fernandes, ampliada por seus discípulos a partir de 1954, ano em que Roger Bastide retorna definitivamente à França e Florestan assume a cadeira (embora oficiosamente até 1964) de Sociologia I. O alvo não poderia ser melhor, já que o prestígio de Gilberto Freyre como autor de Casagrande E senzala tornava-se vulnerável numa obra de pretensão teórica, marcada por "distorções" tão graves. Em contrapartida, afirmava-se mais uma vez o projeto do grupo, de constituir em bases sólidas a sociologia como ciência. A separação radical entre os domínios da ciência e da arte, proposta defendida por Ianni, apóia-se no pressuposto de que somente a ciência dispõe de meios para afastar-se do mundo dos valores, nisso consistindo a diferença de abstração que a separa da literatura. ${ }^{16}$ Por isso, o elogio do sociólogo pernambucano a Proust seria descabido, mas compreensível por estar, na visão do grupo, atrelado a uma visão conservadora do país. A sociologia seria a forma crítica e compatível do pensamento com o processo possível de modernização do país.

O texto de Ianni e a citação de Gilberto Freyre são notáveis para apreendermos a disputa em jogo, que reforça entre nós o argumento de Wolf Lepenies em relação ao desenvolvimento da sociologia na Europa. O autor analisa a competição travada entre literatos e sociólogos pela legitimidade de explicar e orientar o desenvolvimento da sociedade ocidental industrial, intensificada na transição do século XIX para o XX, para concluir que os rumos da sociologia nos três países teriam sido definidos por essa contenda, responsável pelo dilema constitutivo da disciplina: aproximarse da literatura, (numa atitude hermenêutica) ou das ciências naturais (numa atitude cientificista). A argumentação demonstra caso a caso a complexidade do processo, mostrando como o dilema ocorre também no interior de grupos, aparentemente identificados com um dos lados da disputa, e mesmo na trajetória de agentes individuais. Por isso, é necessário muito cuidado para evitar-se a simplificação do problema. Nesse passo, seguimos no item seguinte a interpretação de Sylvia Garcia, em Destino impar (2002), que sublinha a convergência entre as perspectivas de Antonio Candido e Florestan Fernandes. 


\section{Radicais e conservadores}

A consideração da trajetória intelectual de Candido e Florestan efetivamente permite tomá-los como representantes exemplares da contraposição entre a atividade cultural e a atividade científica. Contudo, essa configuração não pode fazer esquecer que estamos diante de duas vertentes que se desenvolvem a partir de uma mesma concepção sobre a atuação do intelectual nas sociedades modernas. Um mesmo projeto, duas formas de realização. Aderindo a uma posição cientificista, Florestan projeta a possibilidade de uma realização radical do radicalismo proposto por Candido (Garcia, 2002, p. 99).

A interpretação da autora indica a necessidade de levar-se em conta, na reconstrução desse contexto acadêmico, uma clivagem de natureza política, profundamente imbricada na anterior, que opõe ao pensamento conservador, predominante no Brasil até a primeira metade do século $\mathrm{XX}$, o pensamento radical, comprometido com a compreensão efetiva da realidade brasileira e orientado pelas possibilidades de sua transformação. Tais objetivos circunscrevem genericamente a inflexão realizada no pensamento social brasileiro, pela institucionalização das ciências sociais em São Paulo, a partir da criação da ELSP e da FFCL-USP, na década de 1930, de acordo com o testemunho recente de Antonio Candido:

A importância da Sociologia e Política e da Faculdade foi deslocar a sociologia brasileira das classes dominantes para as classes dominadas. Os grandes nomes da sociologia brasileira eram Gilberto Freyre e Oliveira Vianna, que estudavam as classes dominantes, na perspectiva da história. A realidade imediata do Brasil contemporâneo foi estudada pela Escola de Sociologia e pela Faculdade em suas camadas humildes. Samuel Lowrie fez a pesquisa sobre o lixeiro; Gioconda Mussolini estudou os caiçaras; eu estudei o parceiro rural; Egon Schaden, o índio destribalizado; Florestan, o negro. Por assim dizer, nós radicalizamos a sociologia brasileira. ${ }^{17}$

Do ponto de vista das disputas políticas, deparamo-nos em primeiro plano com a oposição entre as duas instituições, ELSP e FFCL-USP, que centralizavam o ensino e a pesquisa em ciências sociais no período. ${ }^{18} \mathrm{O}$ processo de criação das instituições já foi estudado (Limongi, 1989; Cardoso,
1982), sendo possível afirmar que ambas atendiam às expectativas da elite paulista de recuperar a hegemonia política perdida nos anos trinta após as Revoluções de 1930 e 1932, mas devemos reter uma diferença importante. A primeira, criada pelo industrial Roberto Simonsen, aproximava-se de setores da elite paulistana ligados ao Partido Republicano Paulista. Sua finalidade principal seria a formação de "técnicos com competência administrativa" (Limongi, 1989, p. 219), daí o ensino baseado em pesquisas de campo, voltadas para o conhecimento "objetivo" da realidade. O projeto da USP, amadurecido desde os anos de 1920 pelo círculo de intelectuais reunido no jornal $O$ Estado de São Paulo (conhecido como grupo do Estado), estava mais próximo do Partido Democrático, pretendendo capacitar intelectualmente uma elite a "decidir os destinos da nacionalidade" (Cardoso, 1982, p. 92), justificando a orientação mais ampla e teórica das ciências sociais da USP. De tal modo, embora as instituições viessem a se autonomizar progressivamente dos objetivos políticos envolvidos na criação de ambas, assumindo orientação cada vez mais acadêmica, é provável que a ELSP significasse para a USP, desde os primórdios, a promessa de um projeto politicamente conservador e intelectualmente limitado.

Nesse sentido, os "estudos de comunidade", principal projeto acadêmico da ELSP, foram recusados pelos sociólogos da USP, especialmente por Octávio Ianni e Maria Sylvia de Carvalho Franco nos anos de 1960, com termos muito próximos aos de Caio Prado Jr em resenha ao livro Cunha, de Emílio Willems, publicada em Fundamentos (1948), revista de cultura vinculada ao PCB. ${ }^{19}$ O fato é muito significativo, não para reduzir a crítica realizada pelos assistentes de Florestan Fernandes aos seus componentes políticos, mas para constatar a imbricação profunda entre ciência e política (aprofundada com o golpe de 1964) que caracterizou os decênios de institucionalização das ciências sociais em São Paulo, apesar da separação crescente entre os domínios, inerente a este processo.

Emílio Willems realizava, como professor das duas instituições, uma espécie de "missão ecumênica”, para reuni-las na construção das ciências sociais em São Paulo. Tal objetivo é perseguido também na direção de Sociologia, ${ }^{20}$ pri- 
meiro periódico especializado em ciências sociais editado no Brasil, que publica textos de professores e alunos das duas escolas, até o afastamento de Willems.

Em 1948 (vol. 10, n. 2), Willems publica o "Symposium sobre classes sociais". ${ }^{21}$ Pierson escreve "Como descobrir o que é classe?"; Willems, "Velhos e novos rumos do estudo de classes sociais", e Florestan, "A análise sociológica das classes sociais" em oposição clara aos primeiros. O confronto explicitaria a disputa entre ELSP e USP e as dificuldades inerentes ao "projeto ecumênico" de Willems. Se o tom acadêmico do debate disfarçava a tomada de posição de Florestan Fernandes, em favor da crítica politizada de Caio Prado Jr. a Cunha, marcava, por outro lado, claramente a divergência entre as diferentes concepções de ensino e pesquisa que caracterizavam as instituições. Na primeira, prevalecia a ênfase na pesquisa empírica etapa indispensável à generalização teórica na visão de Pierson (compartilhada por Willems), assim como no ensino "verdadeiramente científico", isto é, centrado na análise dos processos sociais efetivos e não na história das idéias sociológicas, esta considerada característica dos períodos pré-científicos da disciplina. Na USP, comparativamente, a pesquisa dependeria, nos termos de Willems, ao caracterizar sua própria formação européia, mais da "iniciativa do estudante" do que de uma orientação sistemática fornecida pelos professores. Seria, portanto, resultante da teoria, esta o cerne do ensino, baseado na discussão dos clássicos. Caricaturando, tenderiam (aos olhos dos rivais) à "pura descrição" e à "especulação".

\section{Da teoria aos fatos, dos fatos à teoria}

Willems criticava (acompanhando o argumento do texto de Pierson) o "caráter conjectural e global" de certos estudos sobre classes. O autor insiste no estudo das divisões concretas de cada sociedade, para verificar "como os homens se classificam a si próprios”. Descarta, em seguida, a possibilidade do estudo da estratificação social de uma nação (pensando evidentemente no caso brasileiro), sem o conhecimento prévio de suas partes componentes, afirmando ao mesmo tempo o pressuposto e a proposta centrais dos "estudos de comunidades":

É inteiramente absurda a pretensão de estudar a estratificação de uma nação sem anteriormente investigar a estratificação das unidades ecológicas e culturais em que essa nação se divide (Corrêa, 1995, p. 80)

O texto de Florestan, "A análise sociológica das classes sociais", lembrando que o autor trabalhou na pesquisa que deu origem a Cunha, defende rigorosamente a teoria sociológica das classes sociais, mostrando, em primeiro lugar, que o desenvolvimento da sociologia ocorreu atrelado à sociedade de classes, que se constituiu num dos objetos por excelência da disciplina. A sociedade de classes seria a estrutura social típica do Ocidente, marcada pela complexidade e diferenciação.

A aparência genérica da polêmica tem como referência o caso brasileiro. Isso é importante se lembrarmos o aspecto fundamental do esquema de Caio Prado Jr., que supõe a formação do Brasil, desde a colônia, como resultante da expansão do capitalismo comercial. Tal fato implicaria ao mesmo tempo simultaneidade e atraso (em função da escravidão) no desenvolvimento do capitalismo brasileiro em relação ao europeu, justificando o estudo sobre o desenvolvimento específico da sociedade de classes entre nós.

Pierson e Willems afirmam, contudo, que diferenças históricas profundas inviabilizariam o estudo das classes sociais no Brasil. Florestan defende-se ao afirmar o caráter típico-ideal do conceito, desde Marx e, sobretudo, em Weber. Por isso, embora a dimensão histórica fosse decisiva, a análise sociológica permaneceria legítima.

Criticando os "estudos de comunidade", Florestan Fernandes recusava o empirismo e a ênfase nas diferenças culturais que desviariam o observador do processo decisivo ao desenvolvimento brasileiro a formação da sociedade de classes e defendia com toda força a abordagem macrosociológica, fundamentada na tradição européia da disciplina, fazendo no final uma provocação à sociologia norte-americana, ao associar a interpretação culturalista da estratificação social às "condições de existência social nos Estados Unidos, onde as distinções de classes eram menos pronunciadas e cristalizadas do que nas sociedades européias" 
(Idem, p. 112), repondo com certa ironia a dimensão política da crítica de Caio Prado Jr., que apontara o caráter reacionário de tais análises.

A polêmica mostra como se imiscuem política e ciência no período, sendo a primeira princípio classificatório dos grupos e personagens no campo específico da segunda. É sugestivo, nessa direção, que a crítica dos sociólogos da USP aos "estudos de comunidade" tivesse como pano de fundo a associação entre a ênfase na pesquisa empírica e a orientação conservadora que caracterizaria tal perspectiva. A tentativa fracassada de conciliação entre as duas escolas, ensaiada por Emílio Willems, deve ser compreendida, assim, a partir desse contexto, que, provavelmente, influenciou a decisão do antropólogo alemão de deixar o Brasil e aceitar o convite para trabalhar nos Estados Unidos, na Universidade de Vanderbilt, em 1949. O fato teria como conseqüência o obscurecimento do papel central desempenhado pelo autor de Cunha no contexto que examinamos.

Do ponto de vista de Florestan, o grande equívoco de seus adversários seria tomar a pesquisa empírica como etapa primeira, desconsiderando-se o fato de que a história da sociedade brasileira seria tributária da européia, o que implicaria tomar como ponto de partida para a explicação sociológica da sociedade brasileira as teorias clássicas sobre o desenvolvimento da modernidade, formuladas pela sociologia européia, desde o século XIX. O caso brasileiro seria uma vertente particular, somente compreensível a partir de perspectiva totalizadora, que faria o engate das experiências historicamente articuladas. Tal tese, já esboçada, como vimos, em 1948, constituiria o eixo programático da chamada "Escola sociológica paulista", constituída pelo sociólogo paulista e por seus assistentes e discípulos, reunidos na Cadeira de Sociologia I, a partir de 1954.

A defesa da teoria por Florestan não significa, portanto, o desprezo à pesquisa empírica sistemática, incorporada em sua sociologia, mas a precedência da primeira: "como se sabe, a pedra de toque deste [o trabalho científico] tem sido a seguinte fórmula: nem teoria sem fatos, nem fatos sem teoria" (Fernandes, 1958, p. 222). Mas outro aspecto deve ser notado (cf. Arruda, 2002), a necessidade de se trabalhar em equipe, para lograr a concretização de um novo padrão de cria- ção intelectual, em molde científico e profissional. Neste caso, a iniciativa inspiradora de Donald Pierson na ELSP foi decisiva, influenciando certamente a atitude de Florestan Fernandes de recrutar nos anos de 1950 e 1960 um grupo de jovens e competentes sociólogos, com o intuito de renovar as ciências sociais com um estilo inusitado de trabalho marcado por alta produtividade e coesão de princípios. ${ }^{22}$

\section{Totalidade ou dualidade}

O debate sobre as classes sociais revela ainda a oposição entre modelos de interpretação associados às abordagens "empírica", dos "estudos de comunidade", ou "teórica", dos "estudos societários", como poderíamos definir, contrastivamente, os trabalhos da "escola sociológica paulista". Os primeiros estariam mais próximos das análises de tipo "dualista", que encontram no pensamento social brasileiro Os sertões, como precursor, e em Os dois Brasis, de Jacques Lambert, a expressão mais típica, realizada pelas ciências sociais dos anos de 1950. A característica fundamental de tal modelo propõe a interpretação da formação social brasileira a partir da constatação de diferença profunda entre um Brasil "arcaico" e outro "moderno", movidos por sentidos e temporalidades distintas, freqüentemente confrontados. Os "estudos societários" tomariam como referência, ao contrário, análises "totalizadoras", como a de Caio Prado Jr. na Formação do Brasil contemporâneo, mas principalmente as da sociologia clássica - sobretudo Marx, Weber e Durkheim assimiladas e adaptadas ao estudo da realidade brasileira. O desafio, desta perspectiva, seria compreender o "sentido" e a "forma" (possíveis) da claudicante modernização brasileira, subordinada à européia.

Ainda uma vez tomaremos como parâmetros dessa contenda, que atravessa a formação da sociologia paulista, formulações de Emílio Willems e Florestan Fernandes. ${ }^{23}$

Willems, partindo da tese da heterogeneidade cultural brasileira, avalia em O problema rural brasileiro do ponto de vista antropológico ${ }^{24}$ as possibilidades e as dificuldades inerentes à superação do atraso no mundo rural brasileiro, contrariando 
visões etnocêntricas dos reformadores, que teriam compreendido mal o problema:

Para os médicos, o caboclo é um doente e um sub-alimentado; para o educador todo "mal" reside no analfabetismo; o agrônomo verifica a inexistência de conhecimentos "racionais" de agricultura; os economistas dão pela falta de crédito, de mercados e meios de comunicação, os moralistas desejam erradicar certos "vícios", e assim por diante (Willems, 1943, p. 21).

A questão fundamental, entretanto, passaria desapercebida, dado o desencontro cultural verificado entre os grupos sociais em contato. Definindo "cultura" como um "sistema de entendimentos comuns", o autor afirmava sua inexistência como "base comum à civilização urbana e à multiplicidade de culturas sertanejas" (Willems, 1944 , p. 9). Qualquer tentativa de reforma deveria, portanto, partir do conhecimento aprofundado das formas de sociabilidade e culturais características das populações sertanejas:

[...] essa sociedade possui um tipo (ou tipos) de família e associação vicinal, regimes de trabalho e técnicas destinadas a produzir os artefatos necessários, sistemas de trocas, meios de transporte, práticas tradicionais para lidar com forças sobrenaturais, conhecimentos para tratar doentes e parturientes, jogos e festas para compensar as obrigações que o sistema social impõe a seus membros e uma educação para transmitir o patrimônio cultural (sem que a arte de ler e escrever possa ter uma função na transmissão tradicional). Ao lado de um corpo de conhecimentos, práticas e crenças, destinado a controlar o natural e o sobrenatural, existe um sistema de controle social com sanções específicas. Há mais de quatro séculos que esta sociedade vive, crê, trabalha, se diverte e educa. Não há motivos para se acreditar que seus modos de pensar, agir e sentir tenham sofrido grandes modificações nos quatro séculos de existência. As experiências que seus membros acumularam nesse respeitável lapso de tempo provaram mil vezes ser adequadas, pois não somente garantiram a subsistência dos vivos mas permitiram um aumento incessante da população sertaneja. Durante quatro séculos, o caboclo não deixou de conquistar os sertões e de enchê-los, pouco a pouco, de povoadores (Idem, pp. 9-10).

O reconhecimento da existência autônoma das sociedades sertanejas pelo "civilizado" seria, nesse sentido, o passo imediatamente necessário a qualquer tentativa de intervenção. Deveria levar-se em conta igualmente a dificuldade de alterar aspectos limitados sem que outras esferas da cultura fossem afetadas, com conseqüências de difícil previsão e possivelmente drásticas para os grupos. ${ }^{25} \mathrm{O}$ texto indicava, ainda, um programa de pesquisas a ser realizado, visando à constituição de um amplo painel da sociedade brasileira, que teria em Cunha seu ponto de partida. O dualismo seria, portanto, pressuposto dos trabalhos do autor e da maioria dos estudos de comunidades realizados em São Paulo na década de 1950.

A perspectiva totalizadora de Florestan Fernandes e grupo, já esboçada no simpósio de 1948, pode ser bem apreendida em Sociedade de classes e subdesenvolvimento, de 1967, que sintetizava as teses do grupo até o momento, ao mesmo tempo em que prenunciava o desenvolvimento autoral da temática, concretizada em $A$ revolução burguesa no Brasil. A divergência fundamental em relação a Willems baseia-se na constatação da inadequação de sua proposta em face de problemas sociológicos mais amplos e complexos, como o da explicação do subdesenvolvimento. O texto em questão é de extremo interesse, em primeiro lugar por expressar a "tensão intelectual e moral" (Fernandes, 1981, p. 7) ${ }^{26}$ decorrente do golpe de $1964 .{ }^{27} \mathrm{O}$ autor sublinha a importância do estudo sociológico do subdesenvolvimento, que direcionava o trabalho do grupo, desde o início da década de 1960:

Até hoje, os investigadores dos centros mais avançados lidaram com os problemas de interpretação das sociedades capitalistas dependentes como se o subdesenvolvimento fosse uma contingência ou uma condição transitória. Os investigadores oriundos dessas sociedades perfilharam tal ponto de vista ou negligenciaram a necessidade, puramente teórica, de associar o regime de classes e o capitalismo dependente à explicação sociológica do subdesenvolvimento. (p.13, grifos meus)

Sociedade de classes e subdesenvolvimento parte de algumas "considerações preliminares", esclarecidas após a definição prévia do capitalismo como "complexa realidade sócio-cultural", não redutível apenas aos seus componentes eco- 
nômicos. A primeira consideração refere-se ao processo de formação da sociedade brasileira como "parte da expansão do mundo ocidental e do papel que nele tomaram os portugueses" (p. 21), que retém, não obstante a orientação econômica dada pelo capitalismo comercial, a estrutura social típica da Europa medieval, de regime estamental, fato prolongado apesar da Independência do Brasil, que não altera imediatamente os níveis econômico e social. A transformação econômica ocorreria apenas na forma assumida pelos "laços coloniais", que deixam de ser "jurídico-políticos" para se tornarem econômicos apenas, o que implicaria progressivamente a constituição de um "setor econômico novo e moderno" (p. 23), embora subordinado a interesses externos. A complexidade (e refinamento) do argumento do autor reside no jogo de avanços e recuos que confere inteligibilidade ao processo em questão, aparentemente ambíguo. Na verdade, trata-se de diferenciar efeitos imediatos e mediatos, o que permite a apreensão conjunta e dinâmica de permanências e rupturas.

A conclusão parcial a que chega o autor indica a complexidade do processo histórico brasileiro, marcado por similaridades e diferenças, encontros e desencontros, em relação ao pólo dominante do capitalismo. Nessa direção, movida também pela conjuntura histórica imediatamente posterior ao golpe de 1964, a análise deixa entrever seu objetivo (e sua urgência) político, explicitamente enunciado no prefácio do livro, ao revelar no presente as contradições herdadas do passado:

No plano de nossa análise, essa contradição transparece na consciência falsa do agente econômico, que se representa como um "construtor de impérios econômicos", segundo as regras (na realidade, solapadas ou destruídas pelo capitalismo monopolista e pelo intervencionismo estatal) de um capitalismo avançado, auto-suficiente e autônomo. Na verdade, não passa de um laborioso artífice (e sob vários aspectos de uma vítima) do antípoda desse capitalismo: o capitalismo diferenciado porém subdesenvolvido e dependente, que exprime a espécie de êxito, conquistado na esfera econômica, pelos antigos povos coloniais que nasceram, biológica, cultural e historicamente, da "expansão do mundo ocidental (p. 26).
A dificuldade de superação da dependência residiria no fato de o desenvolvimento servir ao mesmo tempo à integração da economia nacional e à "multiplicação do excedente econômico das economias capitalistas hegemônicas" (p. 36), processo que favoreceria a reprodução da heteronomia. Esta consistiria numa inserção específica no mercado mundial, como "entidade tributária", que implicaria, sob a aparência de "'distorções', 'carências' ou 'deficiências'” (p. 37) em relação ao desejável, a modernização possível das sociedades subdesenvolvidas. Não obstante, no "plano organizatório, a ordem vigente é análoga à existente nas sociedades desenvolvidas, respondendo aos mesmos requisitos formais e ideais de incentivação, coordenação e integração das atividades econômicas, sociais e políticas" (p. 37).

Desse ponto de vista, as análises de cunho dualista seriam incapazes de captar os processos constitutivos da realidade em questão, dessa forma apenas "descrita", mas não compreendida em profundidade. A tese do autor insiste, assim, na lógica própria ao capitalismo dependente, no qual a "persistência de formas econômicas arcaicas" seria essencial à sua reprodução, devemos lembrar, subordinada e precária. O fundamental no quadro exposto, já vimos acima, seria a tendência econômica de reprodução da situação de dependência (mesmo com a industrialização) e não de sua superação. Nesse sentido, justificar-seia também a sobrevivência do "setor arcaico", numa espécie de ciclo vicioso (determinado pela transferência do excedente apenas para o setor moderno e, sobretudo, para fora do país). Assim, o parâmetro geral de análise da estratificação social recai sobre Weber, por enfatizar a oposição no mercado entre "possuidores" e "não possuidores" de bens. ${ }^{28}$ Entre estes, estariam os assalariados e os diversos "condenados do sistema", contrastados por contarem apenas os primeiros com a possibilidade de valorização no mercado, embora limitada pela "situação de classe" desfavorável. Esta, nas condições descritas, implicaria, como vimos, na identificação do trabalhador com a ordem capitalista e na percepção de sua condição como privilegiada. Entre os "possuidores", estariam as "classes altas", segundo representação própria. Florestan diferenciava, então, as frações (classes altas rurais e urbanas) mais próximas 
duma "burguesia" nacional, "únicas classes que contaram, contam e continuarão a contar com condições para tomar consciência clara de seus interesses de classe e de sua situação de classe" (p. 73). A argumentação justifica o interesse analítico pela "burguesia", da qual dependeriam as possibilidades (políticas) de orientar o desenvolvimento em outro sentido, contrário à reprodução da dependência; alternativa dificultada tanto pela ilusão da autonomia política, como pela defesa dos interesses econômicos imediatos. As expectativas de Florestan em relação às classes "não possuidoras", do ponto de vista de sua atuação política, eram pessimistas (embora o autor lembrasse o "risco de violência potencial" representado pelos "condenados do sistema"), sobretudo para o "campesinato".

Em suma, o regime de classes cumpriria na sociedade subdesenvolvida apenas subsidiariamente as funções históricas típicas às sociedades capitalistas independentes. Sem garantir um "mínimo de homogeneidade" social, não permitiria tampouco a percepção autônoma de interesses pelas classes em disputa, de modo que a dinâmica resultante desse processo estaria também comprometida com a persistência dos mecanismos de dependência. Internamente, tal configuração se expressaria na desigualdade social crescente, em "contradições irredutíveis". Em outros termos, a violência seria convertida em forma legítima de ajustamento social, em "estilo de vida", apesar dos esforços em escamoteá-la.

A conclusão do texto discute, sobretudo, as possibilidades da revolução burguesa no Brasil. O autor diferencia dois sentidos para "revolução burguesa": o primeiro associado ao processo de configuração do capitalismo autônomo; o segundo, relativo à "diferenciação e reintegração" da economia capitalista, na passagem do capitalismo comercial ao industrial. Nesse sentido, Florestan avança detalhando o processo brasileiro.

O ponto decisivo da argumentação reside na percepção sociológica do processo como resultado contingente, conseqüência do modo por meio do qual a "burguesia" enfrenta as "tensões econômicas, políticas e sociais" (p. 95) inerentes ao desenvolvimento capitalista (em condição de dependência). Deste ângulo, as coisas poderiam ter sido diferentes, diante das mesmas condições estruturais herdadas da colonização. Ou seja, as possibilidades eram restritas justamente em função da condição de heteronomia, mas existiam e dependiam do alcance da ação histórica da burguesia. A experiência brasileira, entretanto, teria sido marcada por uma "revolução" tímida e egoísta, da qual resultaria o quadro esboçado (que tem como referência as transformações da sociedade brasileira, a partir do processo de Independência) pelo autor ao longo do texto: haveria diferenciação e crescimento econômico, relacionados à formação da "ordem social competitiva", mas não "revolução integral". Tal diagnóstico se sustentaria com a verificação da conjugação das estruturas arcaicas e modernas, reveladora da incapacidade "de romper totalmente com o passado e de eliminar os vínculos de subordinação no plano internacional" (p. 97). A "burguesia" brasileira (e latino-americana) teria, portanto, segundo o autor, falhado diante das condições enfrentadas.

O texto comentado resume a orientação teórica e temática assumida por Florestan Fernandes e por seu grupo nos anos de 1960, centrada na análise sociológica do subdesenvolvimento. Tal programa privilegiava as abordagens caras às sociologias econômica e política; estas eram as dimensões consideradas cruciais à compreensão (e possível transformação) da realidade brasileira. Neste ponto, devemos recuar no tempo para considerar outro programa de pesquisa, sugerido pela atuação acadêmica de Roger Bastide, que apostava na análise sociológica da cultura como o melhor caminho para compreender a formação da sociedade brasileira, subordinada à dominação européia.

\section{Os objetos privilegiados da sociologia: cultura ou desenvolvimento}

Desde já devemos matizar tal oposição lembrando a relação de "mestre e discípulo" que vinculava Roger Bastide e Florestan Fernandes, transformada, ao longo dos anos de 1950, na pesquisa sobre o negro em São Paulo ${ }^{29}$ (patrocinada pela Unesco), em uma das parcerias mais alentadas da história da sociologia brasileira. Em Brancos $e$ negros em São Paulo (Bastide e Fernandes, 1959), 
já se percebe, entretanto, como demonstrou Fernanda Peixoto, a diferença de perspectivas que opõe a primeira parte do trabalho, escrita por Florestan, à segunda, redigida pelo sociólogo francês. Na composição do texto citado, as metades complementam-se, mas indicam ao mesmo tempo estilos de reflexão divergentes: a primeira orientada para as dimensões econômica e política (sendo o racismo expressão, na mentalidade, da transição da sociedade escravista à sociedade de classes), a segunda para as formas de ajuste psicossociais do negro diante da discriminação (diferenciadas em função das possibilidades de ascensão social, progressivamente ampliadas). ${ }^{30}$

Neste caso, portanto, cabe a Florestan a visada geral, o panorama histórico-sociológico que localiza a análise micro, realizada por Bastide. Mas a diferença não se detém aí, apenas revela, sigo novamente os passos de Fernanda Peixoto, modos de apreensão quase opostos dos impasses da modernização ocidental, e do Brasil em particular.

A análise sociológica da cultura englobando religião, arte, literatura, folclore permitiria, para Roger Bastide, plasmar formas de resistência ao processo de modernização. Nesse sentido, as diversas formas sociais e culturais tradicionais não se constituiriam em entraves à modernização, ao contrário, seriam necessárias à revisão crítica de seus pressupostos, marcados por uma visão etnocêntrica e dogmática. Dessa posição, o autor investiga os processos de "interpenetração de civilizações", sobretudo em seus estudos sobre as religiões afrobrasileiras, mas também nas pesquisas sobre folclore, arte etc. Tal perspectiva não é compartilhada por Florestan, que a acompanha apenas do ponto de vista metodológico, na defesa da sociologia como instrumento de análise dos processos culturais e de forma muito tímida em sua dimensão substantiva, no que se refere às potencialidades transformadoras do folclore. Os trabalhos de Antonio Candido e Maria Isaura Pereira de Queiroz, entretanto, devem muito a essa orientação, que abordaremos brevemente a seguir, a partir de Sociologia do folclore brasileiro (Bastide, 1959), comparando suas teses e pressupostos aos de Florestan Fernandes em Folclore e mudança social na cidade de São Paulo, ambos publicados em 1959.

No prefácio de Bastide para "As Trocinhas do Bom Retiro" (Fernandes, 2004), o autor defen- dia a abordagem sociológica de Florestan Fernandes, baseada no estudo das formas de sociabilidade dos grupos infantis, as "trocinhas", às quais relacionava as manifestações folclóricas existentes, discernindo fatores de permanência e de desintegração diante das transformações aceleradas da cidade de São Paulo nos anos de 1940. O prefácio de Bastide revela a concordância de ambos sobre o método, constituindo um programa a ser desenvolvido:

O folclore é uma cultura, ora, não se pode compreender a cultura, separando-a do grupo social que ela exprime. Estamos entre os que acham que a descrição pura e simples do material, a pesquisa das fontes e das origens não são suficientes, porque o folclore tem uma função e uma vida, ele representa um papel. Por conseguinte, querendo penetrá-lo, em lugar de permanecer na crosta exterior das sobrevivências do passado, é preciso recolocá-lo num meio social. O folclore não é uma simples curiosidade ou um trabalho de erudição, é uma ciência do homem - não deve portanto esquecer o homem, ou melhor, neste caso, a criança que brinca. Temos necessidade de que se multipliquem as pesquisas deste gênero. Que não se tema esclarecer uma ciência pela outra. Os amantes da pureza lastimar-se-ão, talvez, mas os amantes da realidade objetiva só terão a ganhar com isso (Idem, pp. 196).

No entanto, para cada autor, o programa serviria a objetivos distintos. Embora não se deva menosprezar, no conjunto da obra de Florestan Fernandes, seus estudos sobre folclore, nem exagerar a descontinuidade destes em relação aos trabalhos posteriores, é possível sublinhar, como faz Sylvia Garcia (2001), sua importância "estratégica” nas disputas disciplinares que marcaram o período. Nesse sentido, o autor assumiria, na polêmica travada com os folcloristas, a linha de frente do combate, por meio do qual afirmaria os pressupostos que informavam a defesa da sociologia como ciência, negando ao folclore o mesmo estatuto. Embora Roger Bastide defendesse, conforme a citação acima, a abordagem sociológica do folclore, sua participação na polêmica é menos incisiva, por legitimar o esforço de afirmação do folclore como disciplina científica, definida pela especificidade de seu objeto. Em tal direção, constituir-se-ia em ramo da antropologia cultural, voltado ao estudo da cultura popular. O funda- 
mental seria não separar na análise formas culturais de formas sociais.

A diferença entre as estratégias dos autores, em defesa da sociologia do folclore é, no entanto, menos importante do que a distância que separa as interpretações substantivas, apreendida por Fernanda Peixoto, perceptível a partir das "molduras" que enquadram as análises dos autores. Em Florestan, a cidade de São Paulo; em Bastide, o Brasil. Embora o interesse inicial por São Paulo do primeiro fosse motivado pelo cruzamento de sua história individual com os problemas suscitados pelo curso de graduação ministrado pelo segundo, tomar a cidade como objeto significava focalizar o processo de mudança social em curso acelerado, em função do qual o folclore se desintegrava. Não obstante, Florestan procurava demonstrar a vitalidade do folclore, sobretudo como fator de ajustamento psicossocial, que minimizaria efeitos disruptivos, caros à urbanização:

\begin{abstract}
Não podemos ignorar, porém, que, por reduzida que seja, a influência positiva do folclore facilita o ajustamento de certos tipos de personalidade ao mundo urbano em transformação e fortalece disposições psicossociais favoráveis à renovação cultural com base na conservação de elementos essenciais à integridade da "civilização brasileira" (Fernandes, 2004, p. 28).
\end{abstract}

Tal conclusão aproxima-se do ponto de vista de Bastide, para quem o folclore (como a religião, a arte, a literatura) seria mais do que fator de ajustamento, seria fator de resistência e recriação social. O autor investiga na formação do folclore brasileiro, desde a colonização, a interação entre as tradições culturais portuguesa, africana e ameríndia. A primeira seria certamente predominante (embora adaptada às condições diversas da colonização, que teriam favorecido a interferência da Igreja católica no processo), mas circunstâncias históricas teriam favorecido, também, a assimilação de tradições negras e indígenas, freqüentemente mobilizadas em resistência à dominação branca. A diferença fundamental entre as interpretações dos autores reside, assim, na aposta feita pelo sociólogo francês na tradição, apreendida a partir da cultura, como objeto privilegiado da sociologia.

$\mathrm{O}$ retorno definitivo de Bastide à França em 1954 implicou a desvalorização progressiva da sociologia da cultura em relação à sociologia do desenvolvimento. ${ }^{31} \mathrm{Na}$ década de 1960 tal oposição assumiria outra forma, marcada pela concorrência entre disciplinas vizinhas: crítica literária e sociologia. Tal contexto, que ultrapassa os propósitos deste artigo, seria marcado também pela radicalização política provocada pelo golpe de 1964, que impediu a realização completa do projeto de Florestan Fernandes e de seu grupo, ao mesmo tempo em que o legitimou, porque o grupo assumiu a linha de frente da oposição à ditadura militar na Universidade de São Paulo.

\section{Notas}

1 Ultrapassa os limites deste trabalho uma discussão teórica aprofundada sobre a forma ensaio. Não se objetiva tampouco tomar partido nessa questão. Importa, sobretudo, verificar como tal tensão organiza o debate intelectual no período.

2 "As ciências sociais desenvolvidas nos quadros universitários redirecionam, então, os critérios de confecção das normas de elaboração das linguagens. No interior do sistema intelectual, as oposições estarão pontuadas pelas diferenças entre reflexões consideradas rigorosas e científicas e aquelas vistas como impressionistas e arbitrárias" (Arruda, 2002, p. 206). Sobre a importância do ensaio na formação do pensamento brasileiro, ver Candido (1976). O mesmo autor avalia a relação entre o ensaio e a sociologia (Candido, 1957).

3 É o que sugere Maria Arminda do Nascimento Arruda: "Independentemente dos procedimentos adotados, o resultado é denso e profícuo. Florestan Fernandes consegue, nesse texto, provavelmente mais do que em outros, elucidar as relações contraditórias subjacentes a uma totalidade composta de elementos em si mesmo diversos. E, aí, aproxima-se de sugestões presentes em obras como Raízes do Brasil, de Sérgio Buarque de Holanda, pois, no prefácio da obra, Antonio Candido chama a atenção para essa capacidade do autor em romper uma visão dicotômica e trabalhar dialeticamente com as oposições" (Arruda, 2002, p. 294).

4 Este aspecto constitui o mote principal da crítica à sociologia paulista realizada no Rio de Janeiro, a partir de textos de Wanderley Guilherme dos Santos.

5 Passagem retirada do memorial de Maria Sylvia de Carvalho Franco, apresentado em 1988 na USP. 
6 Na verdade, os personagens também se afastam ou se aproximam dos dois pólos ao longo da carreira. Assim, as considerações aqui sugeridas devem ser matizadas, para que se evite o extremo da caricatura.

7 Cabe citar: "Em São Paulo, a hierarquia acadêmica que vai se constituindo nas duas primeiras décadas de funcionamento foi sendo modelada por docentes estrangeiros treinados nas regras e costumes da competição acadêmica européia (e francesa em particular), todos eles empenhados em instaurar um elenco de procedimentos, exigências e critérios acadêmicos de avaliação, titulação e promoção. O acesso às posições de comando e liderança esteve invariavelmente condicionado à produção e defesa do doutoramento, ao concurso para livre-docência e à conquista de cátedra, preenchendo-se esses lugares de preferência com licenciados nativos que firmaram sua reputação pela excelência de sua produção intelectual, pela herança presuntiva das posições em aberto com o retorno dos estrangeiros, ou, então, por uma combinação variável de ambos os fatores" (Miceli, 1989, p. 81).

8 No que diz respeito às obras dos cientistas sociais, é necessário realçar as novas modalidades temáticas e, concomitantemente, uma transformação significativa do estilo de exposição. No que se refere aos temas, emergem objetos mais circunscritos, exprimindo o abandono dos grandes panoramas históricos e das análises centradas no render conta dos largos processos de constituição da sociedade brasileira, típicos do ensaio. Isso não significa, no entanto, que se desprezou a busca da compreensão da história brasileira a partir de uma visão de conjunto. O que pretendo salientar é que, apesar do remetimento à totalidade, o foco da análise passa a incidir sobre um problema determinado. Diferentemente dos chamados intérpretes do Brasil, dirigidos para a questão dos fundamentos da sociedade, os sociólogos paulistas buscam compreender as relações entre certos fenômenos e o contexto abrangente. Por isso, os trabalhos monográficos entram na ordem do dia (Arruda, 2002, p. 211).

9 Na vigência do sistema de cátedras (1934-1969), na FFCL-USP, havia duas cadeiras de sociologia. Tal divisão institucional esteve associada, desde o começo da faculdade, a disputas entre concepções distintas de ensino e pesquisa (freqüentemente misturadas a questões de ordem política). Os primeiros catedráticos foram Paul ArbousseBastide (primeira cadeira) e Lévi-Strauss (segunda). Entre os dois, houve um confronto, que pode ser apreendido nos textos de cada um, pu- blicados no primeiro anuário da Faculdade (1935); os programas de curso, publicados no anuário seguinte são também reveladores dessa contenda. A "queda de braço" teve como desfecho o afastamento de Lévi-Strauss, no final de 1937. Para seu lugar, foi contratado Roger Bastide, cujo breve texto, publicado no anuário de 1938, indica a intenção de "estabelecer uma ligação muito estreita entre nosso curso e o de nossos colegas" (p. 14). Bastide seguiu a orientação do programa, lecionando "sociologias especiais". O sociólogo francês teve papel decisivo na FFCLUSP (e no cenário cultural paulista) até seu retorno à França, em 1954. No início da década de 1940, é transferido para a Cadeira de Sociologia I, assumindo a segunda cadeira Fernando de Azevedo (Arbousse-Bastide assume a cadeira de Política). A Cadeira de Antropologia é criada em 1941, regida por Emílio Willems até 1949, em seguida por Egon Schaden e João Batista Borges Pereira. Disputas mais acirradas entre as cadeiras ocorrem a partir da substituição de Bastide por Florestan Fernandes em 1954. Em seguida, as assistentes Gilda de Mello e Souza e Maria Isaura Pereira de Queiroz migram, respectivamente, para a Filosofia e para a Sociologia II. Esta (na qual trabalharam Florestan e Antonio Candido, como assistentes, até 1954 e 1958, respectivamente) caracterizar-se-ia, a partir da segunda metade da década de 1950 , por reunir, sob a cátedra de Fernando de Azevedo (substituído em 1964 por Rui Coelho), sociólogos com orientações teóricas diversas; além de Maria Isaura e Rui Coelho, Azis Simão, por exemplo. Na Sociologia I, prevalece a orientação "científica", imposta por Florestan Fernandes a seus discípulos, entre os quais Fernando Henrique Cardoso, Octávio Ianni, Maria Sylvia de Carvalho Franco e Marialice Forachi. O desenvolvimento da sociologia na USP foi marcado fortemente por essa divisão, pelas disputas entre as cadeiras e internas a elas, sobretudo na Sociologia I, acirradas depois de 1964. Sobre esse contexto, ver Pulici (2004).

10 Seguimos aqui a tese de Heloísa Pontes (1998), remetendo o leitor para o capítulo quatro "Intelectuais acadêmicos".

11 Conforme a passagem seguinte: "Para um sociólogo como Florestan Fernandes, o ensaísmo e a forma literária de escrita estão comprometidos com uma visão estamental da cultura. 'O nosso padrão de vida literária foi moldado numa sociedade senhorial e o escritor passou a ver-se, como e enquanto escritor, à luz de uma concepção estamental do mundo'. Por essa via, o professor constrói uma forma de exposição cujo traço mar- 
cante refere-se à apresentação de um discurso, não apenas permeado por conceitos, mas no qual a precisão da linguagem científica é o principal elemento ordenador" (Arruda, 2002, p. 212). O trecho citado pela autora está em Fernandes (1963, p. 230).

12 Sobre as revistas e sua importância na legitimação dos grupos no período, ver Jackson (2004).

13 Florestan Fernandes defendeu o desenvolvimento da sociologia como ciência, o que não significa que fosse imune às preocupações estilísticas, caras ao ensaio. Em sua obra, há variação em relação às formas de exposição, mais ou menos "científicas", de acordo com os temas e as circunstâncias que marcaram sua trajetória acadêmica e política.

14 Para uma análise circunstanciada dessa obra, ver Pontes (2004)

15 Faltaria, portanto, melhor fundamentação empírica no trabalho da autora, ausência não compensável pelo estilo de escrita.

16 Se abraça certo cientificismo nessa época, Octávio Ianni posteriormente valoriza arte e literatura como interpretações do mundo real. A leitura aqui sugerida não visa à desqualificação de nenhuma das duas perspectivas.

17 Depoimento concedido ao pesquisador em 30/9/1996, transcrito em Jackson (2002).

18 A tensão política que divide o espaço acadêmico, nas décadas de institucionalização das ciências sociais paulistas, será exemplificada aqui, a partir da disputa entre FFCL-USP e ELSP; devemos reter, no entanto, que, internamente à USP, aos grupos e às trajetórias dos personagens, a política atua igualmente como princípio classificatório.

19 Caio Prado afirma na resenha uma relação direta entre o método, baseado em pesquisa empírica rigorosa, e o caráter possivelmente reacionário escondido na proposta aparentemente neutra do trabalho.

20 Sobre Sociologia, ver Limongi (1987). Sobre a trajetória de Willems, ver Villas-Bôas (2000).

21 O debate metodológico sobre estratificação social, constituiu, como notou Mariza Corrêa (1995), um marco decisivo no desenvolvimento das ciências sociais em São Paulo.

22 A partir de então, o trabalho em grupo constituise em requisito fundamental para o trabalho científico. Devemos notar, nesse sentido, que ao assumir a Cadeira de Teoria Literária e Literatura Comparada, na FFCL-USP, em dezembro de 1960,
Antonio Candido trata imediatamente de compor uma equipe de professores e pesquisadores, cujos integrantes mais célebres seriam Roberto Schwarz, Walnice Nogueira Galvão, João Alexandre Barbosa e Davi Arrigucci Junior. Chamamos atenção para o fato de que em literatura, ao contrário do que ocorrera na sociologia, Antonio Candido representaria (em relação aos concretistas sobretudo) uma vertente marcada pela cientificidade, esta perseguida através de procedimentos próprios à crítica literária - "estabelecimento de fontes, de textos, de influências, pesquisa de obras auxiliares, análise interna e externa, estudo da repercussão, análise das constantes formais, das analogias, do ritmo de criação" (Candido, 1963) -, definidos na tese de concurso, defendida em 1945, sobre Silvio Romero, autor que lhe servia de contraponto.

23 Nísia Trindade Lima (1998) aproxima os autores notando, acertadamente, a preocupação de ambos com as possibilidades da sociologia de se constituir como ciência aplicada. Sobre o projeto de Florestan nessa direção, ver Romão (2003).

24 O fato de o texto ter sido publicado na imprensa aponta para o caráter antes político do que científico, o que permitiu ao autor formular teorias sem confirmação anterior em fatos concretos, sobre os quais operaria a construção indutiva.

25 O exemplo dado pelo autor refere-se à possibilidade quase certa de desagregação social diante do impacto da economia capitalista.

26 As citações desta obra (Sociedade de classes e subdesenvolvimento) virão, doravante, no corpo do texto com o número de página entre parênteses.

27 A ditadura militar inviabilizaria a realização completa do projeto "Economia e Sociedade no Brasil - Análise Sociológica do Subdesenvolvimento", direcionado pela possibilidade, defendida por Florestan Fernandes, de a Sociologia constituir-se como ciência aplicada; no contexto, voltada ao estudo dos obstáculos ao desenvolvimento brasileiro, para o qual pretendia contribuir. O golpe levaria o autor a assumir posição política mais evidente por exemplo, ao antecipar teses ainda não suficientemente embasadas, como no texto em questão, atitude típica de sua concepção, diante das circunstâncias, da sociologia como ciência "crítica e militante" (cf. Fernandes, 1976 [1963]).

28 Os termos entre aspas remetem a categorias mobilizadas por Florestan.

29 A relação entre os autores foi estudada em profundidade por Fernanda Peixoto (2000), cuja aná- 
lise nos orienta neste momento. Tomamos também como referência o texto de Maria Isaura Pereira de Queiroz, "Nostalgia do outro e do alhures" (1983). Sobre o projeto Unesco, remetemos o leitor ao texto de Marcos Chor Maio (2000).

30 A correspondência entre os autores constitui documento histórico precioso, sobretudo no que se refere ao andamento da pesquisa da Unesco, quando Bastide dividia-se entre o Brasil e a França. Tivemos acesso às cartas de Bastide (pelo que agradecemos novamente a equipe eficiente $\mathrm{e}$ prestativa da Biblioteca comunitária da UFSCAR), das quais reproduzimos duas passagens significativas. A primeira, de carta redigida em 26/1/1952, na qual Bastide relatava os compromissos que, em Paris, o afastavam do trabalho na pesquisa, destaca a importância que depositavam no trabalho, tanto para a tomada de consciência do problema racial, como para o desenvolvimento da sociologia brasileira: "Mas tudo isso me toma muito tempo, e eu só tenho a noite para me ocupar do nosso trabalho coletivo. Espero que, para você, o trabalho ande bem e estou certo de que vamos fazer algo interessante para nós dois e que honrará a sociologia paulista!". A segunda (4/3/1952) propõe uma revisão conjunta do trabalho: "Com efeito, as diversas partes do trabalho são tão ligadas entre si que nós podemos nos repetir em vários pontos. É necessário, então, revermos juntos o relatório, para que possamos lhe dar uma unidade harmoniosa, sem repetições, nem possíveis contradições".

31 A transferência de Antonio Candido para a faculdade de Letras, no final dos anos de 1950, pode ser interpretada como resposta a tais circunstâncias. e o catolicismo rústico brasileiro.

\section{BIBLIOGRAFIA}

ARRUDA, Maria Arminda do Nascimento. (2002), "Florestan Fernandes e a sociologia de São Paulo", in Metrópole e cultura: São Paulo no meio século XX, São Paulo, Edusc.

BASTIDE, Roger. (1959), Sociologia do folclore brasileiro. São Paulo, Anhambi.

BASTIDE, Roger \& FERNANDES, Florestan. (1959), Brancos e negros em São Paulo. São Paulo, Nacional.
CANDIDO, Antonio. (1949), "Resenha de Organização social dos Tupinambá”. Revista do Museu Paulista (nova série), III.

(1957), "A Sociologia no Brasil", in Enciclopédia Delta Larousse, vol. IV, São Paulo, Delta Larousse.

(1963), Introdução ao método crítico de Silvio Romero. São Paulo, Universidade de São Paulo.

(1976), "Literatura e cultura de 1900 a 1945", in Literatura e sociedade, São Paulo, Nacional.

CARDOSO, Irene. (1982), A Universidade da Comunhão Paulista. São Paulo, Cortez.

CORRÊA, Mariza. (1995), "A antropologia no Brasil (1960-1980)", in Sergio Miceli, (org.), História das ciências sociais no Brasil, São Paulo, Sumaré/Idesp/Fapesp, vol. 2.

FERNANDES, Florestan. (1947), "As trocinhas do Bom Retiro". Revista do Arquivo Municipal, cXIII, mar./abr.

(1949), "Resenha de Raízes do Brasil". Revista do Arquivo Municipal, cxxII, fev.

(1952), "Resenha de A moda no século XIX: ensaio de sociologia estética". Anhembi, 25, dez.

(1958), "O padrão de trabalho científico dos sociólogos brasileiros", in A etnologia e a sociologia no Brasil, São Paulo, Anhambi.

(1963), A sociologia numa era de revolução social. São Paulo, Nacional.

(1976 [1963]), A sociologia numa era de revolução social. 2 ed. Rio de Janeiro, Zahar.

(1981), Sociedade de classes e subdesenvolvimento. Rio de Janeiro, Zahar.

(2004), Folclore e mudança social na cidade de São Paulo. São Paulo, Martins Fontes. 
GARCIA, Sylvia. (2001), "Folclore e sociologia em Florestan Fernandes". Tempo Social, 13 (2), nov.

. (2002), Destino impar. São Paulo, Editora 34.

IANNI, Octávio. (1958), "Resenha de Sociologia, introdução ao estudo de seus principios". Anhembi, 92, jul.

JACKSON, Luiz Carlos. (2002), A tradição esquecida: Os parceiros do rio Bonito $e$ a sociologia de Antonio Candido. Belo Horizonte, Editora da UFMG.

(2004), "A sociologia paulista nas revistas especializadas". Tempo Social, 16 (1)

LIMA, Nísia Trindade. (1998), Um sertão chamado Brasil. Rio de Janeiro, Revan/Iuperj.

LIMONGI, Fernando. (1987), "Revista Sociologia: a ELSP e o desenvolvimento da sociologia em São Paulo". Caderno Idesp Série História das Ciências Sociais, 1.

(1989), "Mentores e clientelas da Universidade de São Paulo", in Sergio Miceli (org.), História das ciências sociais no Brasil, São Paulo, Vértice/Idesp, vol. 1.

MAIO, Marcos Chor. (2000), "O projeto Unesco e a agenda das ciências sociais no Brasil dos anos 40 e 50". Revista Brasileira de Ciências Sociais, 14 (41).

MICELI, Sergio (org.). (1989), História das ciências sociais no Brasil. São Paulo, Vértice/Idesp, vol. 1.

PEIXOTO, Fernanda. (2000), Diálogos brasileiros. São Paulo, Edusp.

PONTES, Heloísa. (1998), Destinos mistos. São Paulo, Companhia das Letras.

(2004), "Modas e modos: uma leitura enviesada de O espírito das roupas". Cadernos Pagu, 22.

PULICI, Carolina. (2004), De como o sociólogo deve praticar o seu ofício: as Cátedras de Sociologia da USP entre 1954 e 1969.
São Paulo, dissertação de mestrado, Departamento de Sociologia da USP.

QUEIROZ, Maria Isaura Pereira de. (1983), "Nostalgia do outro e do alhures: a obra sociológica de Roger Bastide", in (org.), Roger Bastide, São Paulo, Ática (col. Grandes Cientistas Sociais, n. 37).

ROMÃO, Wagner de Melo. (2003), A experiência do CESIT: sociologia e política acadêmica nos anos 1960. São Paulo, dissertação de mestrado, Universidade de São Paulo, Departamento de sociologia.

VILLAS-BÔAS, Gláucia. (2000), "De Berlim a Brusque, de São Paulo a Nashville: a sociologia de Emílio Willems entre fronteiras". Tempo social, 12 (2).

WILLEMS, Emílio. (1944), O problema rural do ponto de vista antropológico. São Paulo, Secretária da Agricultura, Indústria e Comércio do Estado de São Paulo.

(1943), "A solução do problema rural brasileiro como mudança social provocada". Sociologia, 5 (2). 

TENSÕES E DISPUTAS NA SOCIO-
LOGIA PAULISTA (1940-1970)

Luiz Carlos Jackson

Palavras-chave: Sociologia paulista; Intelectuais; Ensaio; Ciência; Disputas acadêmicas.

Este artigo interpreta as décadas de formação da sociologia paulista (1940-1970) a partir das principais disputas entre instituições, grupos e atores ocorridas nesse contexto, unificado pela tentativa de explicar a recalcitrante modernização brasileira. Nessa direção, as sociologias específicas progressivamente constituídas eram antes perspectivas de análise do que especialidades propriamente ditas. Esta exposição toma como referência pares de alternativas, em torno dos quais se divergia então: ensaio e ciência, pensamento radical e conservador, teoria e pesquisa empírica, interpretações totalizadoras e dualistas, sociologia do desenvolvimento e da cultura. Com base nessas oposições, que não devem ser compreendidas rigidamente, as tensões constitutivas do período são demarcadas.

\section{TENSIONS AND DISPUTES IN THE PAULISTA SOCIOLOGY (1940- 1970)}

Luiz Carlos Jackson

Keywords: Sociology in the state of São Paulo; Intellectuals; Essay; Science; Academic disputes.

This paper interprets the formation decades of the Paulista sociology (1940-70) in the light of the main disputes among institutions, groups, and agents occurred in this context, which was unified by the attempt of explaining the recalcitrant Brazilian modernization. Following this direction, the specific sociologies, which had been gradually constituted, were primarily analysis perspectives and not specializations themselves. The exposition takes alternative pairs as references, which involved oppositions such as: essay vs. science; radical thinking vs. conservative thinking; empirical theory vs. empirical research; totalizing interpretation vs. dualist interpretation; Sociology of Development vs. Sociology of Culture. The tensions that make up the period are delimitated from those oppositions, which should not be rigidly understood.

\section{TENSIONS ET DISPUTES DANS LA SOCIOLOGIE PAULISTE (1940- 1970)}

Luiz Carlos Jackson

Mots-clés: Sociologie pauliste; Intellectuels; Essai; Science; Disputes académiques.

Cet article propose une interprétation des décennies de formation de la sociologie (1940-1970) à partir des principales disputes entre institutions, groupes et acteurs qui ont eu lieu dans ce contexte, unifié par l'essai d'expliquer la récalcitrante modernisation brésilienne. Suivant cette perspective, les sociologies spécifiques, constituées progressivement, étaient des perspectives d'analyse plutôt que des spécialités à proprement parler. Cet exposé prend comme référence des paires d'alternatives autour desquelles il y avait divergence: essai et science; pensée radicale et conservatrice, théorie et recherche empirique, interprétations totalitaires et dualistes, sociologie du développement et de la culture. Fondé sur ces oppositions, qui ne doivent pas être comprises de façon stricte, les tensions constitutives de la période sont démarquées. 